\title{
Thermo-Poroelastic Analysis of Induced Seismicity at the Basel Enhanced Geothermal System
}

\author{
Sandro Andrés ${ }^{1}\left(\mathbb{D}\right.$, David Santillán ${ }^{1, *} \mathbb{C}$, Juan Carlos Mosquera ${ }^{2} \mathbb{C}$ and \\ Luis Cueto-Felgueroso ${ }^{1}$ (1) \\ 1 Department of Civil Engineering: Hydraulics, Energy and Environment, Universidad Politécnica de Madrid, \\ 28040 Madrid, Spain; sandro.andres@upm.es (S.A.); luis.cueto@upm.es (L.C.-F.) \\ 2 Department of Continuum Mechanics and Theory of Structures, Universidad Politécnica de Madrid, \\ 28040 Madrid, Spain; juancarlos.mosquera@upm.es \\ * Correspondence: david.santillan@upm.es
}

Received: 8 November 2019; Accepted: 29 November 2019; Published: 4 December 2019

\begin{abstract}
Geothermal energy has emerged as an alternative to ensure a green energy supply while tackling climate change. Geothermal systems extract the heat stored in the Earth's crust by warming up water, but the low rock permeability at exploitation depths may require the hydraulic stimulation of the rock fracture network. Enhanced Geothermal Systems (EGS) employ techniques such as hydro-shearing and hydro-fracturing for that purpose, but their use promotes anthropogenic earthquakes induced by the injection or extraction of fluids. This work addresses this problem through developing a computational 3D model to explore fault reactivation and evaluating the potential for earthquake triggering at preexisting geological faults. These are included in the model as frictional contacts that allow the relative displacement between both of its sides, governed by rate-and-state friction laws and fully coupled with thermo-hydro-mechanical equations. We apply our methodology to the Basel project, employing the on-site parameters and conditions. Our results demonstrate that earthquakes which occurred in December 2006 in Basel (Switzerland) are compatible with the geomechanical and frictional consequences of the hydraulic stimulation of the rock mass. The application of our model also shows that it can be useful for predicting fault reactivation and engineering injection protocols for managing the safe and sustainable operation of EGS.
\end{abstract}

Keywords: geothermal energy; induced seismicity; fault; Basel; poroelasticity

\section{Introduction}

The 2030 Agenda for Sustainable Development, adopted by world leaders in September 2015, was established by the United Nations and comprises 17 goals and 169 targets to be fulfilled by the ratifying countries. The Agenda aims to overcome all forms of poverty, while tackling climate change and environmental protection. Goal 7-“Affordable and Clean Energy"-aims to ensure access to affordable, reliable, sustainable, and modern energy for all [1]. Goal 7 goes hand-in-hand with Goal 13, "Climate Action", which aims to take urgent action to combat climate change and its impacts. Geothermal energy emerges as an alternative renewable energy to reach both goals [2,3], as it is affordable and clean. Geothermal systems extract the heat stored in the Earth's crust by warming up water or a mixture of water and gas. The fluid is circulated down through injection wells, heated by the contact with rocks, and returned to the surface through production wells to form a closed loop $[4,5]$. Hot water or steam is then transformed into a marketable product, such as electricity. Nevertheless, in most geothermal reservoirs, rock permeability at exploitation depths is very low, rendering geothermal projects economically infeasible. The challenge of permeability enhancement has been addressed by the so-called Enhanced Geothermal Systems (EGS) [2,6,7]. 
EGS enhance rock permeability through hydraulic stimulation of the rock mass fracture network. Two approaches are widely used: hydro-fracturing, which creates new fracture networks, and hydro-shearing, that reactivates preexisting joints [8,9]. A major environmental issue for these techniques is the risk of induced seismicity as a result of water injection and production [2]. Some major EGS experiences include the Soultz-sous-Forêts project (France) [10], the Cooper Basin project (Australia) [11], the Fenton Hill project (New Mexico, USA) [12], the Rosemanowes project (UK) [13,14], or the Ogachi project (Japan). Furthermore, a number of EGS demonstration projects have recently been launched in the US [15].

Hydro-fracturing, or hydraulic fracturing, enhances rock permeability by opening preexisting fractures and creating new ones. Water is injected within the rock mass under high pressure to open and create the new fractures by tensile failure [16-19]. This technique is broadly used for oil-well stimulation, although it is currently under debate due to environmental concerns [2]. Hydro-shearing increases rock permeability by initiating shear failure. Water is injected under high pressure, reducing normal stress across them and eventually triggering shear failure [9]. Since fault roughness guarantees slip is permanent after injection stops, permeability changes are also permanent [20]. The magnitude of seismic events triggered during hydro-shearing operations is typically small because fractures slip without increasing their aperture as the pore pressure remains bellow the minimum principal stress. Nonetheless, hydro-shearing is widely used on a global scale when conducting field experiments [21] and numerical simulations $[8,22,23]$ to assess permeability evolution.

Most of the scientific community accepts that induced earthquakes may be triggered by water injection into the subsurface. Some examples are the disposal by injection into deep wells of waste water from oil and gas production [24,25], $\mathrm{CO}_{2}$ sequestration in deep aquifers [26,27], or EGS facilities [28,29]. Earthquakes are the result of a fast slip event on a fault [30]. The onset of the slip depends on the shear stress on the fault and the frictional resistance, both of them affected by fluid injection [31]. On one hand, the increase in pore pressure puts effective stress on the fault decrease, whereas on the other hand, thermo-poro-mechanical effects increase shear stress on the fault [32,33]. The experience gained over the years on EGS projects has shown the usefulness of numerical models for simulating the nucleation and rupture of earthquakes under given injection protocols. Numerical simulations of induced earthquakes require coupling fluid flow, rock deformation, heat transfer, and a fault frictional response [34-36]. Highly nonlinear frictional laws and the disparity in time scales pose a major challenge for computational models. Over the past decade, there have been numerous contributions to thermo-hydro-mechanical modeling of induced seismicity [33,37]. Faults are typically simulated as 3D failure zones with slip-weakening rheology [38-40], or as frictional contact surfaces [41-46]. We adopt the latter approach, since it is consistent with the observed structure of faults [47]. We simulate faults as contact surfaces whose friction evolves according a rate-and-state friction law [48] that incorporates terms depending on the evolution of effective normal stress [49,50]. Our results suggest that injection protocols are relevant so they can be designed to minimize seismic risks [51].

A paradigmatic case is the Deep Heat Mining (DHM) project in Basilea (Switzerland) [52,53], a milestone EGS power station with an energy output capacity of $6 \mathrm{MW}$ of electricity and $17 \mathrm{MW}$ of heat. The station would provide electricity and heat for 10,000 dwellings [54]. The project required the drilling of two wells, Basel-1 at $5.000 \mathrm{~m}$ deep to inject cool water, and another well to return hot water back to the surface [55]. Once the former was built, hydraulic stimulation was performed in December 2006. However, it led to perceivable induced seismicity up to a local event magnitude of $M_{L}$ 3.4, which exceeded the acceptable levels in the Basel urban area [56]. The seismic events led to the premature halt of the project, and finally, its withdrawal.

Here, we develop a fully implicit and monolithically coupled finite element model to simulate fault reactivation. Our model encompasses fully coupled heat transport, rock deformation, and fluid flow processes. Moreover, we describe fault as interfaces whose friction is governed by a laboratory derived rate-and-state friction law incorporating an effective normal stress-rate dependence. We analyze the effects of hydraulic stimulation on seismic risk through a Coulomb failure analysis. Measure of 
tendency to slip has proven very useful to understand some of the geomechanical challenges posed by subsurface energy technologies (e.g., [46,57-64]). We aim to analyze the hydro-shearing effects during the stimulation at the Basel-1 well using our three-dimensional (3D) model. We use, as input, the same stress-field and rock properties estimated for the main hydrogeological units at Basel-1, and simulate the stimulation using a transient well-head pressure and flow evolution similar to the values reported at the study site. The proposed model is a useful tool for engineers and practitioners to answer the essential question for the development of the geothermal energy as an affordable, clean, and safe renewable energy source: what is the optimal exploitation protocol that minimizes seismic risk and maximizes economic and energy performance?

\section{Materials and Methods}

In this section, we describe our thermo-hydro-geomechanical model, which fully couples heat transport, rock deformation, and fluid flow; faults are described as interfaces with friction governed by the rate-and-state law. We perform numerical simulations of the hydraulic stimulation operations conducted at the DHM project in December 2006 to show the ability of our model to characterize fault reactivation. We adopt as inputs the recorded well-head pressure and flow evolutions, as well as on-site material parameters.

\subsection{Frictional Strength and Resistance of Faults}

We employ the Amontons-Coulomb theory as a constitutive model of rock friction. The frictional strength, $\tau^{*}$, that impedes sliding of a static, cohesionless contact interface is given by $\tau^{*}=\mu|\sigma|[65-67]$. In general, the relation between these Coulomb magnitudes and the shear stress acting on the contact plane, $\tau$, depends on the sliding regime. A static interface satisfies $\tau \leq \tau^{*}$ and for sliding under quasi-static conditions, the relationship $\tau \approx \tau^{*}$ holds.

In the fluid-saturated media, frictional strength is defined using the effective normal stress, $\sigma^{\prime}=\sigma+p$, where $\sigma$ is the total normal stress acting on the contact, and $p$ is the pore pressure of the fluid. In the above and following expressions, tensile stresses are positive, and pore pressure is positive when above the atmospheric value. We assume that effective normal stresses remain compressive on contact surfaces.

\section{Rate-and-State Models for Interfaces}

Faults are often assumed to be well-oriented for failure but locked prior to injection, in such a way that the onset of slip on an inactive fault-reactivation—is essential to understand the geomechanics of induced seismicity.

Rate-and-state formulations gather the traditional concepts of static and dynamic friction by including the dependence of $\mu$ on the slip velocity and history of sliding [66,68-70]. These models were derived from laboratory experiments of unidirectional slip in the double-direct shear configuration, and account the response of $\mu$ after step changes in slip velocity or normal stress [71]. For a frictional interface that is sliding at velocity $V$, the definition of $\mu$ reads:

$$
\mu=\mu^{*}+a \ln \left(\frac{V}{V^{*}}\right)+b \ln \left(\frac{\theta}{\theta^{*}}\right)
$$

where $\mu^{*}$ is the steady-state coefficient at the reference slip velocity $V^{*}, a$ is the direct-effect parameter, and $b$ is the friction evolution parameter. $\theta$ is the state variable, and $\theta^{*}=D_{c} / V^{*}$ is its steady-state value, where $D_{c}$ is the characteristic slip memory distance over which $\tau^{*}$ evolves once the system is perturbed [72].

Several definitions for $\theta$ have been proposed according to the rate-and-state friction models. Deep physical understandings and theoretical analyses $[70,73,74]$, as well as comparisons with experiments of velocity steps [75,76], shear stress steps [77], and normal stress steps [78-81] have 
allowed us to elucidate the relative advantages and disadvantages of the proposed formulations. Our study focuses on those models that incorporate a dependence on the effective normal stress rate. In such a sense, the Linker-Dieterich model [49] generalizes the basic rate-and-state laws by including a term in the state evolution equation, applicable to both the "slip" [69] and "aging" [68] laws [73]:

$$
\left\{\begin{array}{l}
\frac{d \theta}{d t}=-\frac{V \theta}{D_{c}} \ln \frac{V \theta}{D_{c}}-\frac{\alpha \theta}{b \sigma^{\prime}} \frac{d \sigma^{\prime}}{d t} \quad \text { (Slip law) } \\
\frac{d \theta}{d t}=1-\frac{V \theta}{D_{c}}-\frac{\alpha \theta}{b \sigma^{\prime}} \frac{d \sigma^{\prime}}{d t} \quad \text { (Aging law) }
\end{array}\right.
$$

In the above equations, the empirical parameter $\alpha$ controls the stressing-rate effect on the state variable, ranging from 0 to $\mu_{0}$ [82]. Since we focus on the reactivation of faults which are initially at rest, we adopt a regularization of the rate-and-state models in the limit of zero slip speed, $V=0$, proposed by Yang et al. [83]. $\mu$ is then defined as:

$$
\mu(V, \theta)=\mu_{0}+a \ln \left(\frac{V+V^{*}}{V^{*}}\right)+b \ln \left(\frac{\theta V^{*}}{D_{c}}\right),
$$

with $\mu_{0}$ being the initial friction coefficient. We implement in our model the equation for the aging law:

$$
\frac{d \theta}{d t}=1-\frac{\theta\left(V+V^{*}\right)}{D_{c}}-\frac{\alpha \theta}{b \sigma^{\prime}} \frac{d \sigma^{\prime}}{d t}
$$

which is equivalent to the regularized model used by Tal et al. [84] with a threshold velocity $V^{\text {th }}=V^{*}$.

\subsection{Thermo-Hydro-Mechanical 3D Model of Fault Reactivation}

The rock is modeled as a thermo-poroelastic saturated material with single-phase flow. We adopt the classical theory of linear poroelasticity $[85,86]$ and solve for the combination of fluid pressure, rock deformation, temperature, and frictional contact on the fault [31,32]. The solid and mass conservation, as well as mechanical equilibrium are coupled using the effective stress. The quasi-static Biot equations for a porous medium read:

$$
\begin{gathered}
\rho_{f} S \frac{\partial p}{\partial t}+\rho_{f} \alpha_{B} \frac{\partial \varepsilon_{v}}{\partial t}=\nabla \cdot\left(\rho_{f} \frac{k}{\eta_{f}}\left(\nabla p-\rho_{f} \mathbf{g}\right)\right), \\
\nabla \cdot \sigma=\mathbf{0}
\end{gathered}
$$

where $\alpha_{B}$ is the Biot coefficient, $\varepsilon_{v}=\operatorname{tr}(\varepsilon)$ (with $\varepsilon$ being the infinitesimal strain tensor) is the volumetric strain, $k$ is the intrinsic permeability of the porous medium, $\eta_{f}$ is the fluid dynamic viscosity, $\rho_{f}$ is the fluid density, $p$ is the pressure field, and $\sigma$ is the total stress tensor. We consider a linear poroelastic material under small deformations, as well as plane strain conditions. Then, the effective stress tensor, $\sigma^{\prime}=\sigma+\alpha_{B} p \mathbf{I}$, is a linear function of strains, $\sigma^{\prime}=2 G \varepsilon_{e l}+\lambda \operatorname{tr}\left(\varepsilon_{e l}\right) \mathbf{I}$, where $\lambda$ and $G$ are the Lamé constants, $\varepsilon_{e l}=\varepsilon-\varepsilon_{t h}=\frac{1}{2}\left(\nabla \mathbf{u}+\nabla \mathbf{u}^{T}\right)-\varepsilon_{t h}$ is the elastic strain tensor, the result of subtracting the thermal strains to the total strain tensor $\varepsilon$, with $\mathbf{u}$ being the displacement field. The storage coefficient, $S=\phi \chi_{f}+\left(\alpha_{B}-\phi\right) \chi_{s}$, depends on the rock porosity, $\phi$, and on the fluid and solid matrix compressibilities, $\chi_{f}$ and $\chi_{s}$, where $\chi_{s}=\left(1-\alpha_{B}\right) / K$, and $K=\lambda+\frac{2}{3} G$ is the bulk modulus of the porous matrix. 
Conservation of energy reduces to the heat equation [87]:

$$
\begin{gathered}
(\rho c)_{s a t} \frac{\partial T}{\partial t}+\rho_{f} \mathcal{C}_{f} \mathbf{v} \cdot \nabla T+\nabla \cdot \mathbf{q}=Q, \\
\mathbf{q}=-\kappa_{s a t} \nabla T \\
(\rho c)_{\text {sat }}=\phi \rho c_{s}+(1-\phi) \rho_{f} \mathcal{c}_{f}, \\
\kappa_{\text {sat }}=\phi \kappa_{s}+(1-\phi) \kappa_{f},
\end{gathered}
$$

where $c_{S}$ is the heat capacity of the rock, $c_{f}$ is the fluid heat capacity, $\kappa_{S}$ is the thermal conductivity of the rock, and $\kappa_{f}$ is the fluid thermal conductivity. $(\rho c)_{\text {sat }} \mathrm{y} \kappa_{\text {sat }}$ are the saturated values of the product of density by heat capacity and thermal conductivity. $Q$ includes the source or sink terms. Temperature changes propagate by diffusion and convection throughout the rock mass and the fluid. This changes produce thermal strains controlled by the thermal expansion coefficient $\alpha_{T}$ :

$$
\varepsilon_{\boldsymbol{t h}}=\alpha_{T}\left(T-T_{0}\right),
$$

where $T$ is the temperature field, $T_{0}$ is the reference initial temperature, and $\alpha_{T}$ is the solid thermal expansion coefficient. We consider that the fluid keeps in a liquid state and its properties do not change with temperature or pressure, due to the high temperature and pressure conditions at the usual depths of the EGS projects. This couples the diffusive part of heat transport, while the convective part is modeled by introducing the Darcy velocity field $\mathbf{v}$ in Equation (7).

\subsection{Case Study: The Deep Heat Mining Project in Basel, Switzerland}

The DHM project in Basel was a milestone in geothermal energy. The know-how gained after the DHM project and the seismic events of 2006 boosted the development of EGS systems [52,53]. The first stage of the project was drilling the $5000 \mathrm{~m}$ depth Basel- 1 well. The well reached a crystalline granitic rock basement at a temperature of $200{ }^{\circ} \mathrm{C}$. The well was also employed for the hydraulic stimulation of the reservoir and the field characterization [56].

The number of fractures between $4629 \mathrm{~m}$ and $5000 \mathrm{~m}$ depth was between 0.2 and 0.3 fractures per meter [56]. The preferred fracture direction and orientation were NW-SE to NNW-SSE with dips greater than $60^{\circ}$, although the measures of the hypocenter locations during seismic events detected new families of fractures [88]. The events with greatest magnitude which rolled around in 2006 took place on a family with a deviation of $10^{\circ}$ with respect of the maximum principal stress direction and a dip of $80^{\circ}$. The orientation of the principal stresses was deduced from acoustic geophysical studies within the Basel- 1 well. The minimum principal stress, $\sigma_{h, m i n}$, had an orientation of $54 \pm 14^{\circ}$ and the maximum one, $\sigma_{h, \max }, 144 \pm 14^{\circ}$ [88]. These orientations are consistent with the in situ stress state in the upper Rhine Basin deduced from previous seismic events in the crystalline rocky massif [56].

The magnitude of the principal stresses were also quantified. The tectonic ratio of the minimum principal stress, $\sigma_{h, \min }$, to the vertical one is 0.7 , and the ratio of the maximum principal stress, $\sigma_{h, \max }$, to the vertical one is 1.6, in such a way that the vertical stress is the intermediate principal stress [56]. Mechanic boundary conditions are defined by the expressions:

$$
\begin{gathered}
\sigma_{v}(d)=\left(\rho(1-\phi)+\rho_{f} \phi\right) g d, \\
\sigma_{h, \text { min }}(d)=\operatorname{Tect}_{\text {min }} \cdot \sigma_{v}=0.7 \sigma_{v}, \\
\sigma_{h, \text { max }}(d)=\operatorname{Tect}_{\text {max }} \cdot \sigma_{v}=1.6 \sigma_{v},
\end{gathered}
$$

where $d$ is the depth. In these expressions, compressive stresses are assumed positive. The imposed stresses at the boundaries are assumed constant in time, which is a feasible hypothesis even if simulation time exceeds one decade [89]. The temperature at the bottom of the well is between 190 and $200{ }^{\circ} \mathrm{C}$, with a thermal gradient of $40{ }^{\circ} \mathrm{C} / \mathrm{km}$ [55]. 


\subsection{The Basel 3D Model}

The geometry of the 3D model domain is a $1.5 \mathrm{~km}^{3}$ cube that is supposed to be homogeneous porous rock mass. In the center of the cube, we situated a sphere divided into two hemispheres with their intersection plane representing the main fault. The injection well is modeled as a cylinder with a diameter of $1 \mathrm{~m}$ and a height of $380 \mathrm{~m}$ whose geometry is subtracted from the solid cube. The well is vertical and located at a distance $50 \mathrm{~m}$ away from the center of the fault (Figure 1). The diameter of the simulated well is higher than the real one due to mathematical issues, where the diffusion of the injected fluid should not be simulated with elements which are too fine. The geometry of the model is described in Figure 1.

a

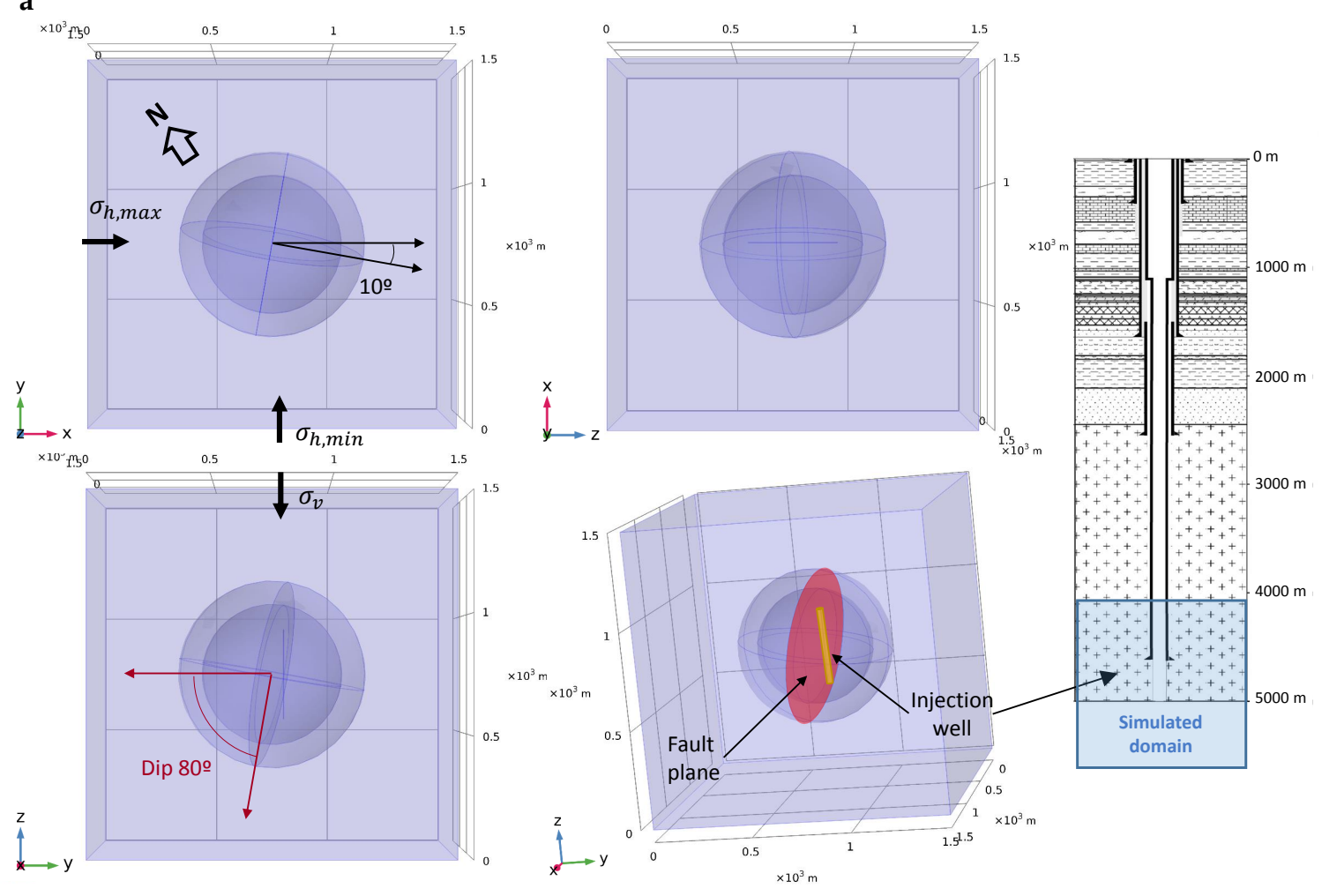

b

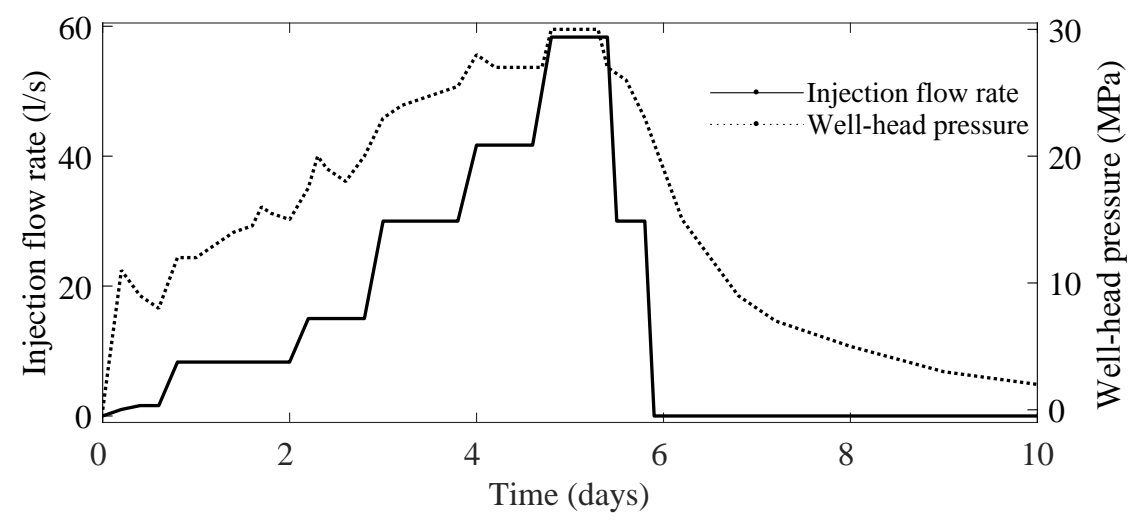

Figure 1. Scheme of the 3D Basel EGS model. In (a) we show the domain that is a $1.5 \mathrm{~km}^{3}$ cube with the fault plane oriented $10^{\circ}$ with respect to the $x$-axis and dip $80^{\circ}$ to the SW. The domain is located between 4050 and $5550 \mathrm{~m}$ depth, while the injection section of the Basel- 1 well extends from 4629 to $5000 \mathrm{~m}$ depth. In (b) we plot the injection protocol (left vertical axis) and injection pressure (right vertical axis) measured at the Basel-1 well, obtained from [56]. 
We focus on the depth range between 4050 and $5550 \mathrm{~m}$, and the injection takes place through the well between 4620 to $5000 \mathrm{~m}$ depth. The $x$ axis is parallel to the maximum principal stress $\left(\sigma_{x}=\sigma_{h, \max }\right)$, the $y$ axis to the minimum principal stress $\left(\sigma_{y}=\sigma_{h, m i n}\right)$, and the $z$ axis to the intermediate principal stress. We apply vertical stress to simulate overburden strata according to $\sigma_{v}(z)=\left(\rho(1-\phi)+\rho_{f} \phi\right) g(5500-z)$, where the $z$ coordinate ranges between 0 and $1500 \mathrm{~m}$ in our model.

The complexity of the fracture network requires the adoption of some simplifications to define the orientation of the fault plane, based on the hypocenter locations estimated from the motion data records of the historical seismic activity [88]. We adopt the most unfavorable fracture family as the preferred sliding plane, which has a direction deviated approximately $10^{\circ}$ with respect to the direction of the maximum principal stress, which dips $80^{\circ}$ towards the SW. Most of the detected hypocenters do not separate more than $50 \mathrm{~m}$ with respect to the upper injection section of the well [55]. For that reason, the fault plane of the model is oriented $10^{\circ}$ with respect to the $x$-axis and dipping $80^{\circ}$ to the $\mathrm{SW}$, with the injection well-located at a distance $50 \mathrm{~m}$ away from its center. We refine the mesh of the model in the area of the central sphere, as shown in Figure 2, and force mesh conformity throughout the fault plane. We use tetrahedral elements-quadratic for the solid mechanics equations and linear for fluid flow and heat transport.

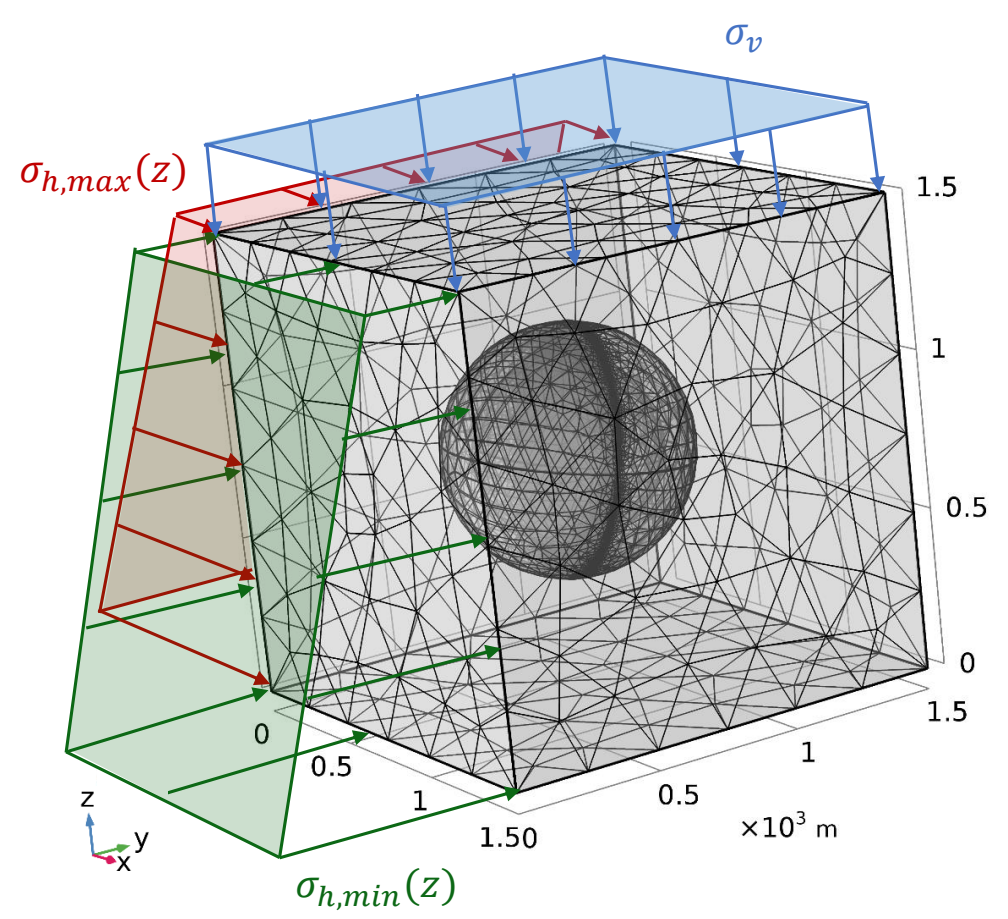

Figure 2. 3D finite element mesh and mechanical boundary conditions applied. At the exterior boundaries with no stresses applied, we impede the displacement in its normal direction.

Mechanic boundary conditions are equal to tectonic stresses and are imposed on three faces of the rectangular domain (Figure 2). We impose a reference hydrostatic pressure, $p=\rho_{f} g d=\rho_{f} g(5550-z)$, along all external boundaries, where $d$ is the depth, and the temperature is set at the geothermal gradient $\mathrm{T}=0.04\left[\mathrm{C}^{\circ} / \mathrm{m}\right] \cdot d=0.04\left[\mathrm{C}^{\circ} / \mathrm{m}\right] \cdot(5550-z)$.

We impede the displacements in the normal direction and impose no-flow (thermal and hydraulic) conditions on the other ones. At the fault plane, we impose the contact condition, allowing relative tangential displacements between its edges. We consider the fault is almost impermeable and has the same thermal properties as the rest of the domain, resulting in thermal continuity. We simplify the fluid flow around the injection well by imposing a volumetric flux along the boundary of an effective injection region (the lateral surface of the cylinder). During the simulations, temperature is also fixed in the injection well. 
Based on the in-site measurements, we define feasible parameters for each physical process of the model.

The Young modulus, the Poisson ratio, and the density of the solid skeleton are usual values for crystalline rock formations of granitic type. The parameters related to the fluid, such as density or compressibility of water, are also usual values, unlike viscosity, whose value of $2.4 \times 10^{-4} \mathrm{~Pa} \cdot \mathrm{s}$, is lower than the viscosity of water at ambient temperature $\left(\eta_{f}=10^{-3} \mathrm{~Pa} \cdot \mathrm{s}\right)$ due to the high temperatures at such depths [23]. Permeability and porosity have been chosen according to the characteristics of the rock mass. Lastly, thermal parameters have been taken from [90] that collects data of thermal conductivities and heat capacities from different materials. Coupling between the flow and mechanical problems have been included using the Biot coefficient $\alpha_{B}=1$ and between the thermal and mechanical physics with the thermal expansion coefficient $\alpha_{T}=8 \times 10^{-6}$.

The parameters of the "rate-and-state" model have been chosen within a feasible range to emulate the fault reactivation at a similar time scale. We consider the fault is arrested before reactivation, being the slip speed $V=0$. Hence, Equations (1) and (2) can be simplified, so it is only necessary to define the parameters $\alpha, b, D_{c}$, and $V^{*}$. We adopt the aging law and the rate-and-state parameters, $b=0.03$, $D_{c}=700 \mu \mathrm{m}, V^{*}=10^{-9} \mathrm{~m} / \mathrm{s}$, and $\mu_{0}=0.55$. Table 1 lists the parameters of the model.

Table 1. Parameters of Basel 3D model.

\begin{tabular}{lccl}
\hline Parameter & Value & Unit & Description \\
\hline$E$ & 20 & $\mathrm{GPa}$ & Young Modulus of the rock \\
$v$ & 0.25 & - & Poisson ratio of the rock \\
$\rho$ & 2700 & $\mathrm{~kg} / \mathrm{m}^{3}$ & Rock Density \\
Tect $_{\text {max }}$ & 1.6 & - & High tectonic ratio \\
Tect $_{\text {min }}$ & 0.7 & - & Low tectonic ratio \\
$\sigma_{h}$ & $\sigma_{v} \cdot$ Tect & $\mathrm{MPa}$ & Confinement stress \\
\hline$\rho_{f}$ & 1000 & $\mathrm{~kg} / \mathrm{m}^{3}$ & Fluid density \\
$\eta_{f}$ & 0.00024 & $\mathrm{~Pa} \cdot \mathrm{s}$ & Fluid viscosity \\
$\chi_{f}$ & $4 \times 10^{-10}$ & $\mathrm{~Pa}-1$ & Fluid compressibility \\
$k$ & $10^{-15}$ & $\mathrm{~m}{ }^{2}$ & Porous media permeability \\
$\phi$ & 0.1 & - & Porosity \\
\hline$\kappa_{S}$ & 2.4 & $\mathrm{~W} /(\mathrm{m} \cdot \mathrm{K})$ & Solid thermal conductivity \\
$\kappa_{f}$ & 0.6 & $\mathrm{~W} /(\mathrm{m} \cdot \mathrm{K})$ & Fluid thermal conductivity \\
$c_{S}$ & 800 & $\mathrm{~J} /(\mathrm{kg} \cdot \mathrm{K})$ & Solid heat capacity \\
$c_{f}$ & 4200 & $\mathrm{~J} /(\mathrm{kg} \cdot \mathrm{K})$ & Fluid heat capacity \\
$\mathrm{T}_{a m b}$ & 293.15 & $\mathrm{~K}$ & Ambient temperature \\
\hline$\alpha_{B}$ & 1 & - & Biot coefficient \\
$\alpha_{T}$ & $8 \times 10^{-6}$ & - & Thermal expansion coefficient \\
\hline$\mu_{0}$ & 0.55 & - & Friction coefficient \\
$c$ & 0 & $\mathrm{MPa}$ & Contact cohesion \\
$a$ & 0.005 & - & Direct effect parameter \\
$b$ & 0.03 & - & Friction evolution parameter \\
$D_{c}$ & 0.0007 & $\mathrm{~m}$ & Characteristic slip distance \\
$V^{*}$ & $10^{-9}$ & $\mathrm{~m} / \mathrm{s}$ & Reference velocity \\
$\alpha$ & 0.2 & - & Linker-Dieterich normal stress coefficient \\
\hline & & &
\end{tabular}

The constitutive laws for fault strength are given by Equations (1) and (2), and the frictional contact on the fault is modeled using an Augmented Lagrangian formulation [91]. We solve, in a monolithically-coupled fashion, the field Equations (5)-(8) and the rate-and-state aging law (1) and (2) with the frictional contact variables [31,32]. 


\section{Results and Discussion}

\subsection{Calibration}

The hydraulic stimulation of the DHM geothermal project required the injection of $11,600 \mathrm{~m}^{3}$ of water, following the protocol depicted in Figure 1b [56]. This volume was injected prior to the 8 December 2006 earthquake sequence. Since we simulated the on-site conditions during the injection operations, we imposed an inflow velocity at the injection well of the model that is the result of dividing the flow rate by the lateral surface of the cylinder $q_{i n y}=Q_{0} /(2 \pi r h)$, where $r$ is the radius of the cylinder and $h$ is the height where injection takes place. We assumed that the injection temperature remained constant and equal to ambient rock temperature.

Figure $3 a, b$ shows a plot of the simulated evolutions of pressure and injected flow rate computed with our model, and the registered data at the Basel-1 injection well in 2006. We adopted as the flow boundary condition the measured injected flow rate at the injection well (see Figure 3a). Our computed injected pressure evolution initially differs from the measured values on-site, Figure $3 b$. The difference between pressure observed in real data and model results arises from the weakening and fracturing of the rock in the vicinity of the well, allowing water to flow through the rock matrix and its fractures. After 5 days of injection, when the largest earthquakes occurred, the difference between our simulated results and the measured data were drastically reduced, showing that our model is properly adjusted.
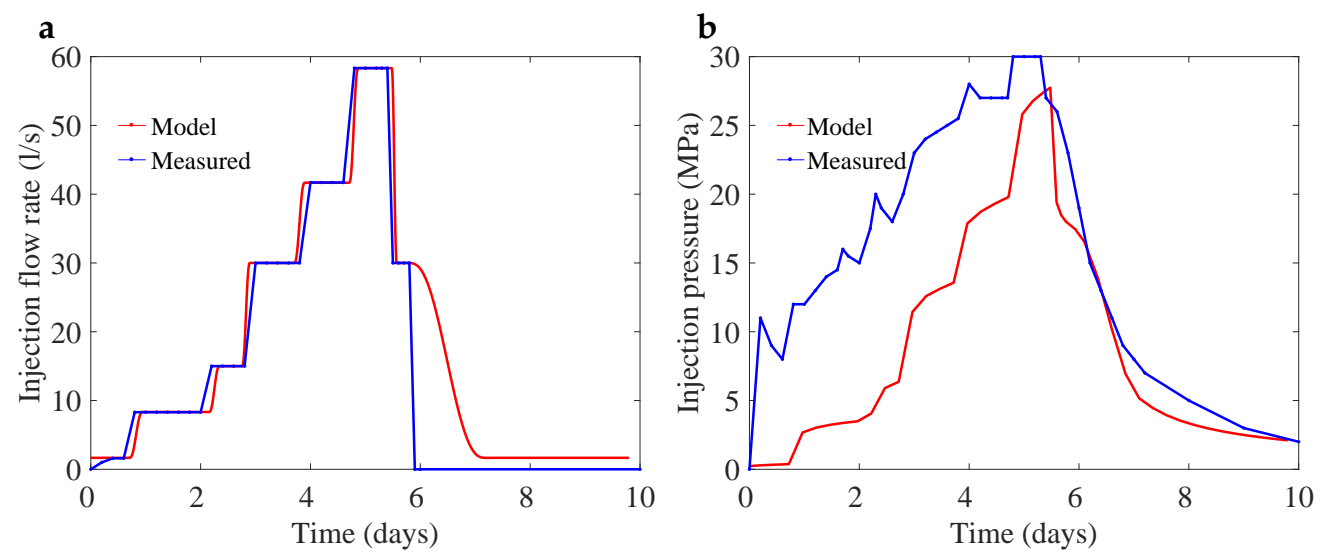

Figure 3. 3D model calibration results. In (a) we show the injection flow rate pattern used in the model (red line) that is similar to the real injection protocol from the Basel-1 data (blue line). In (b) we plot the computed injection pressure (red line) and the values measured in 2006 (blue line).

The results of pore pressure and temperature fields are included in Figure 4. We define a reference horizontal plane at $4800 \mathrm{~m}$ depth $(z=750 \mathrm{~m})$, where the changes of pore pressure and temperature cause by the injection of cold water are displayed. We show in Figure 4 a the locations of the reference plane, the fault plane, and the injection well. We also include the buildup of pore pressure around the injection well and near the fault plane at the time that reactivation occurs $(t=5.5$ days). The injection cools down a small area around the well which does not reach the fault (Figure $4 \mathrm{~b}$ ). Since the time for heat diffusion is higher than the one for pressure diffusion, pore pressure changes around the well are much faster than temperature changes. As fault temperature remains constant during the stimulation phase (Figure $4 b$ ), pore pressure increases on the fault plane (Figure $4 c$ ). We explain in the next section how pore pressure on the fault plane controls the fault reactivation and the frictional properties of the contact. 
a

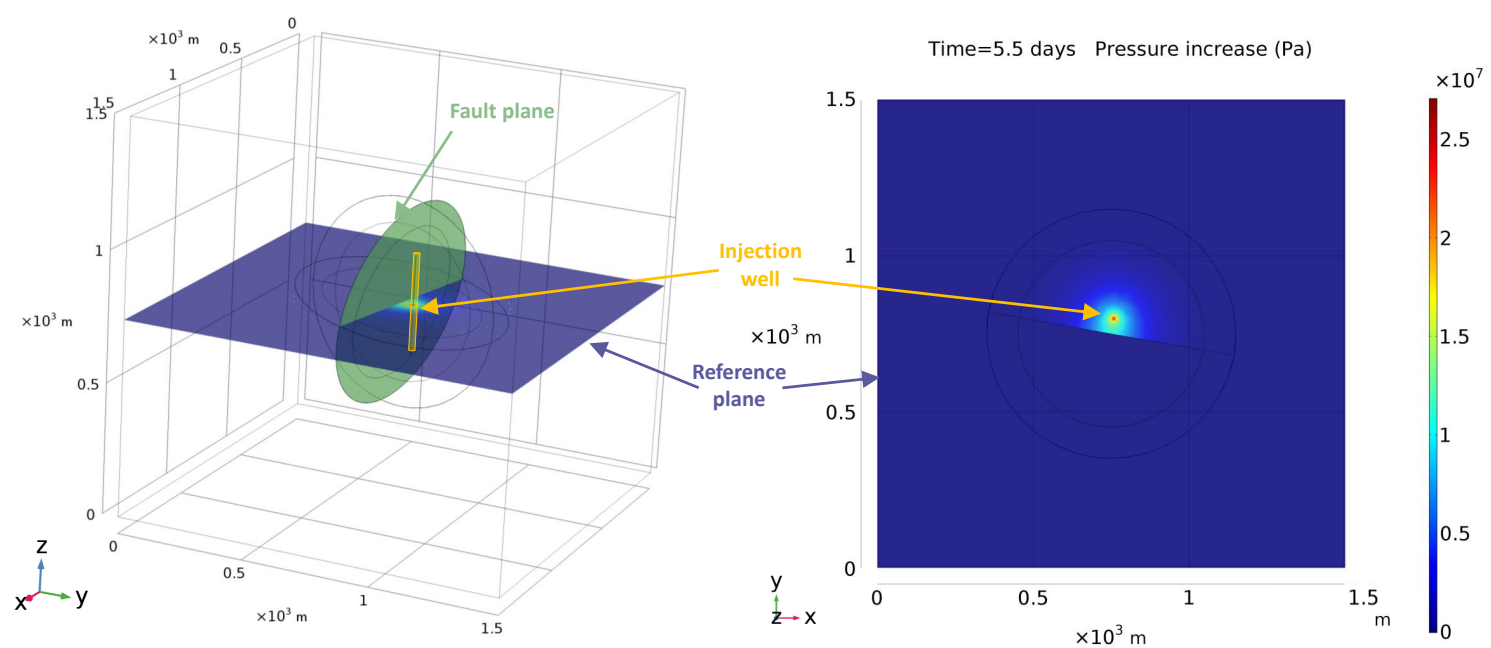

b
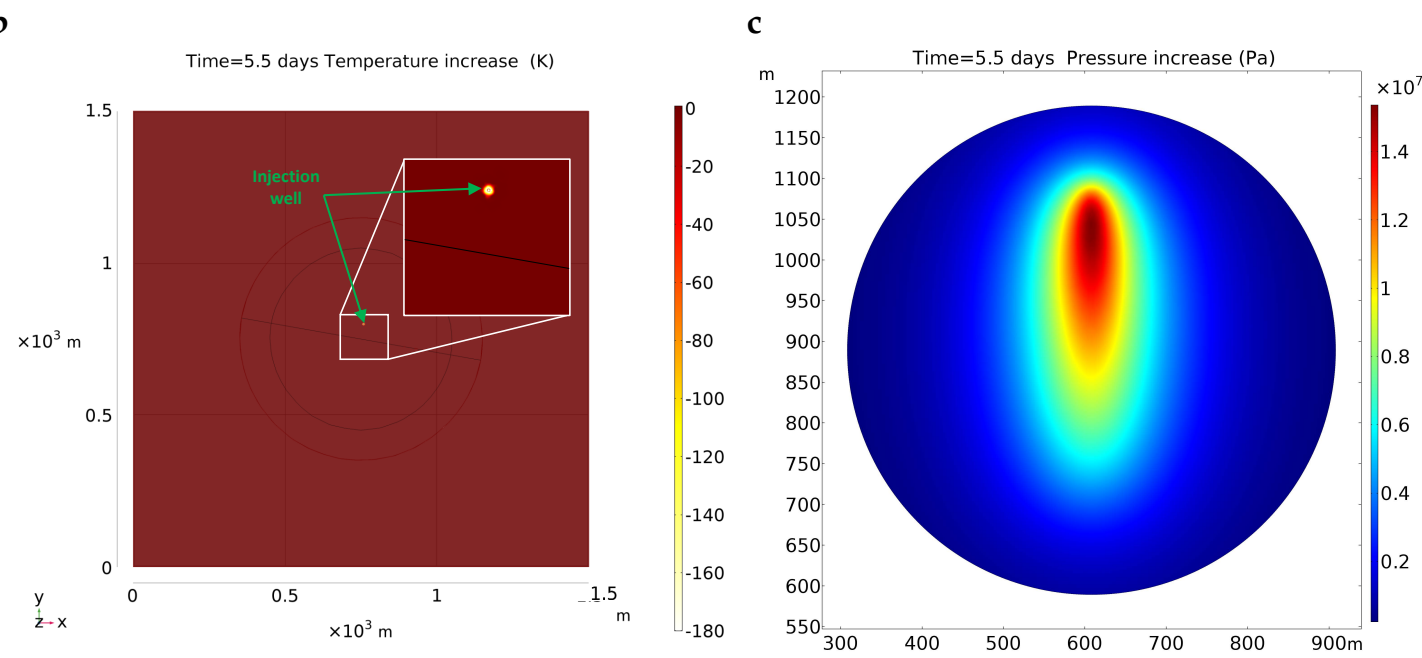

Figure 4. 3D model results at the horizontal reference plane. In (a) (left) we show the reference plane inside the model, the fault plane, and the injection well. The increase of pore pressure (right) in that plane shows the results of the pore pressure increase caused by the injection at the instant of fault reactivation (among $26 \mathrm{MPa}$ ). In (b) we display the increment of temperature due to the injection at the reference plane, with an inset that zooms the surroundings of the injection well and shows that the temperature diffusion is much slower than pressure propagation. In (c) we show the results of the pore pressure increase at the fault plane. The vertical axis of the image corresponds to the maximum slope line of the fault plane and the horizontal axis corresponds to a horizontal direction in the 3D model deviated $10^{\circ}$ with respect to the $\mathrm{x}$-axis.

\subsection{Fault Reactivation}

Fault reactivation is the onset of fault slip. It depends on the variables involved in fault stability, such as frictional strength $\mu\left|\sigma^{\prime}\right|$ or shear stress $\tau$. We quantify fault stability through the Coulomb Failure Function, defined as CFF $=\mu\left|\sigma^{\prime}\right|-\tau$. The CFF equals to zero when the fault is at rest, and when CFF is less than zero the fault reactivates, given that the shear stress $\tau$ exceeds the frictional strength of the contact $\mu\left|\sigma^{\prime}\right|$. Changes in Coulomb Failure Function can be used as a proxy for fault weakening $(\triangle C F F<0)$ or strengthening $(\triangle C F F>0)$. In that sense, we show in Figure 5 the increase in the failure function $\triangle C F F=C F F(t)-C F F(t=0)$ on the fault plane, which indicates how the fault weakens due to the effect of fluid injection. 


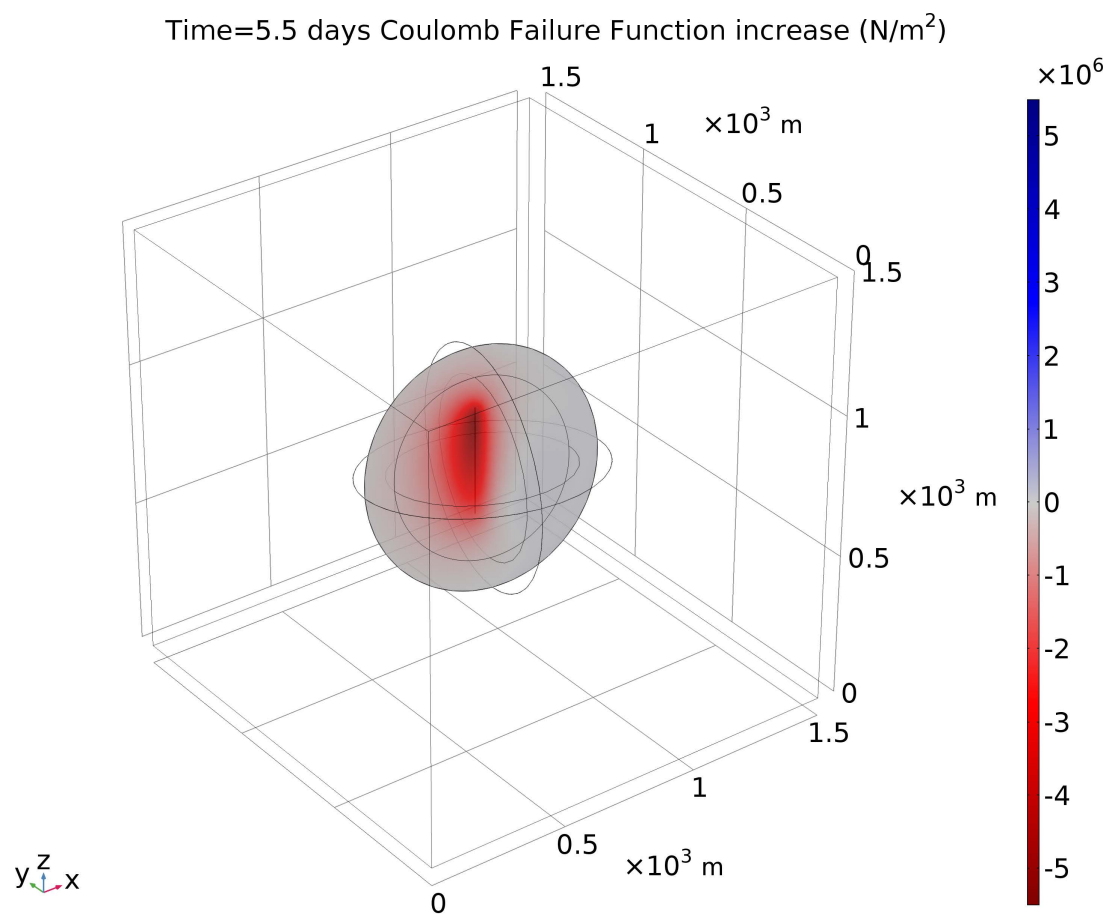

Figure 5. 3D model results on the fault plane 5.5 days after the onset of injection (the instant of fault reactivation). We display the increase in Coulomb Failure Function on the fault plane due to the injection $\triangle C F F=\Delta\left(\mu\left|\sigma^{\prime}\right|-\tau\right)=C F F(t)-C F F(t=0)$. The results show the fault weakening (red color, $\triangle C F F<0$ ) due to the injection of cold water.

We include in Figure 6 our computed results with the 3D model for the variables involved in the frictional stability on the fault plane. The distribution of effective normal stress, $\left|\sigma^{\prime}\right|$, acting on the fault plane (Figure 6a) at the onset of the slip shows that there is a decrease in fault effective compressions. Moreover, the spatial distribution is symmetric with respect to a vertical axis. The decrease in effective normal stress is almost the same as the increase in pore pressure (Figure 4c). Differences arise from poroelastic and thermal effects, and indicate that pore pressure changes dominate over thermal and poroelastic effects.

We plot the modulus of the shear stress $\tau$ on the fault at reactivation time in Figure $6 \mathrm{~b}$. Shear stress increases on the north side of the fault and decreases on the right side. This response is caused by the increase in pore pressure, as well as by the poroelastic effects accounted in our model [16-19,31,32]. The poroelastic effects are also coupled with the fault orientation and tectonic stresses, which contribute to the asymmetry of the results.

We show the value of the friction coefficient, $\mu$, in Figure $6 \mathrm{c}$, computed with the rate-and-state law (Equatons (3) and (4)). Since the fault is initially at rest $(V=0)$, the observed evolution of the friction coefficient is attributed to the decrease in the effective stress through the Linker-Dieterich term and the $\alpha$-parameter in Equation (2) [79]. The Coulomb Failure Function CFF, Figure $6 \mathrm{~d}$, indicates that fault reactivation occurs after 5.5 days of injection. The asymmetry in the CFF distribution remarks the influence of shear stresses, in contrast with the symmetry of effective normal stress and friction coefficient that are directly pore-pressure dependent. This pattern of symmetry and asymmetry of stresses before and at reactivation also influence on the nucleation and rupture phases of the earthquake. 
a
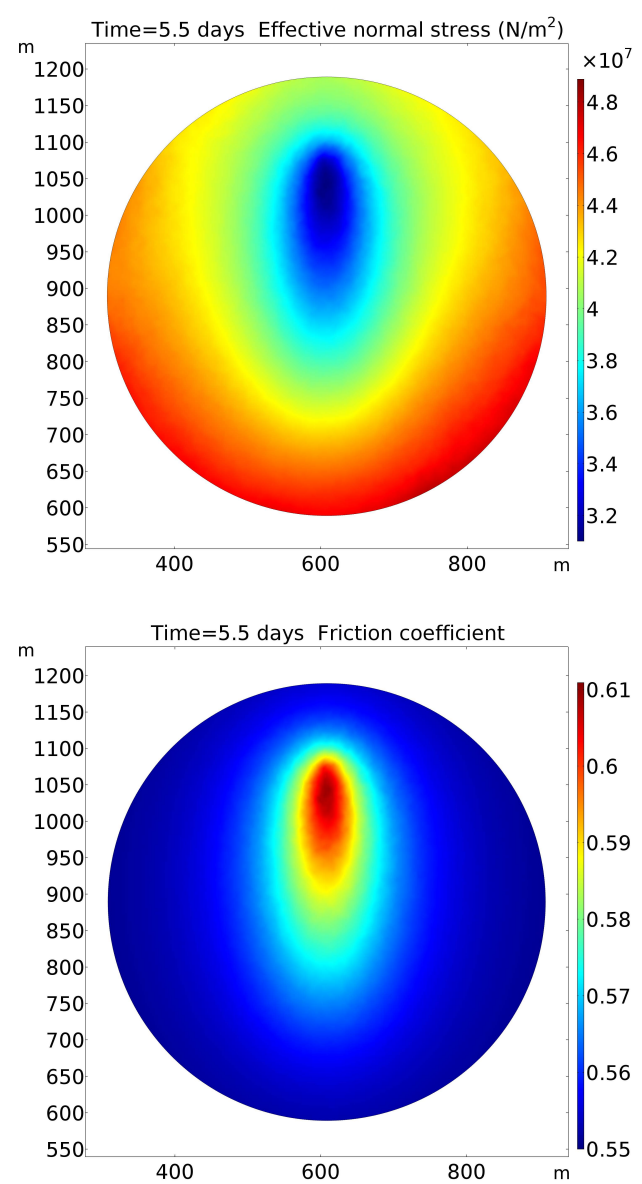

b

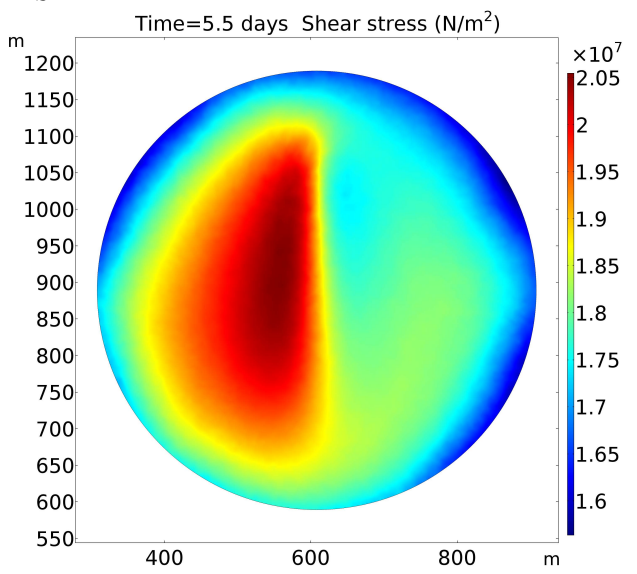

d

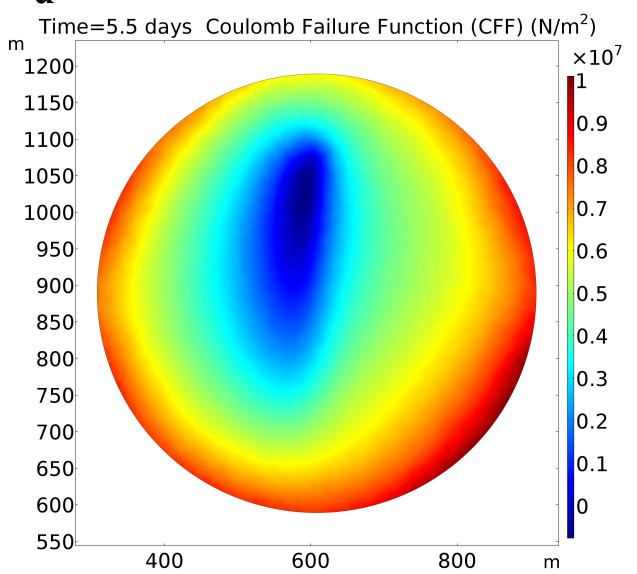

Figure 6. Display of $3 \mathrm{D}$ model results at the $2 \mathrm{D}$ fault plane 5.5 days after the injection starting (the instant of fault reactivation). In (a) we show the effective normal stress $\left|\sigma^{\prime}\right|$ (positive values of effective normal stresses are compressive). In (b) we display the modulus of the shear stress $\tau$, in (c) the friction coefficient $\mu$ obtained from the rate-and-state equations, and in (d) the Coulomb Failure Function CFF.

We illustrate the evolution of stresses and frictional variables up to the fault reactivation at a control point on the fault. The point is located at the left-half part of the fault, and it is the first point where the ratio of the acting shear stress to the effective normal stress equals the frictional strength - that is, it is the first fault point at which slip occurs (blue area where CFF $=0$ in Figure 6d).

Figure 7 shows the evolution of the friction at the control point up to the reactivation. The mobilized friction (green line) is the ratio $\tau /\left|\sigma^{\prime}\right|$ that normalizes the shear stress acting on the fault with the effective normal stress, and the friction coefficient $\mu$ (blue line) is a dimensionless frictional strength. When the mobilized friction equals frictional strength at 5.5 days $\left(\tau /\left|\sigma^{\prime}\right|=\mu\right)$, the fault reactivates.

We observe that due to the injection protocol that systematically increases the flow rate, and consequently, the pore pressure, the slopes of both the friction coefficient and the mobilized friction curves increase. Moreover, the friction coefficient changes from $\mu_{0}=0.55$ to 0.61 at the reactivation instant due to the effect of the variation of the effective normal stress on the friction coefficient. It delays the fault reactivation, which changes from 4.6 days if effective normal stress rate is disregarded, and to 5.5 days if the rate is accounted for. Therefore, the effect of normal stress rate on friction coefficient needs to be taken into account, as it partially controls the reactivation time. These results verify that our models properly reproduce the on-site reactivation of the reservoir's representative fault after 5.5 days of injection, elapsed from December 3 to 8. 
Our methodology may be a useful tool for engineers, practitioners, and stakeholders to assess fault reactivation under real conditions of natural stresses, temperatures, and injection protocols. The application of our model to the DHM project in Basel has shown its ability to predict fault reactivation and demonstrated that the earthquake sequence occurred in December 2006 may have been caused by the hydraulic stimulation of the rock mass. Our model can also be useful for assessing new injection protocols, as well as stimulating and managing the operation of EGS system in the short and long term.

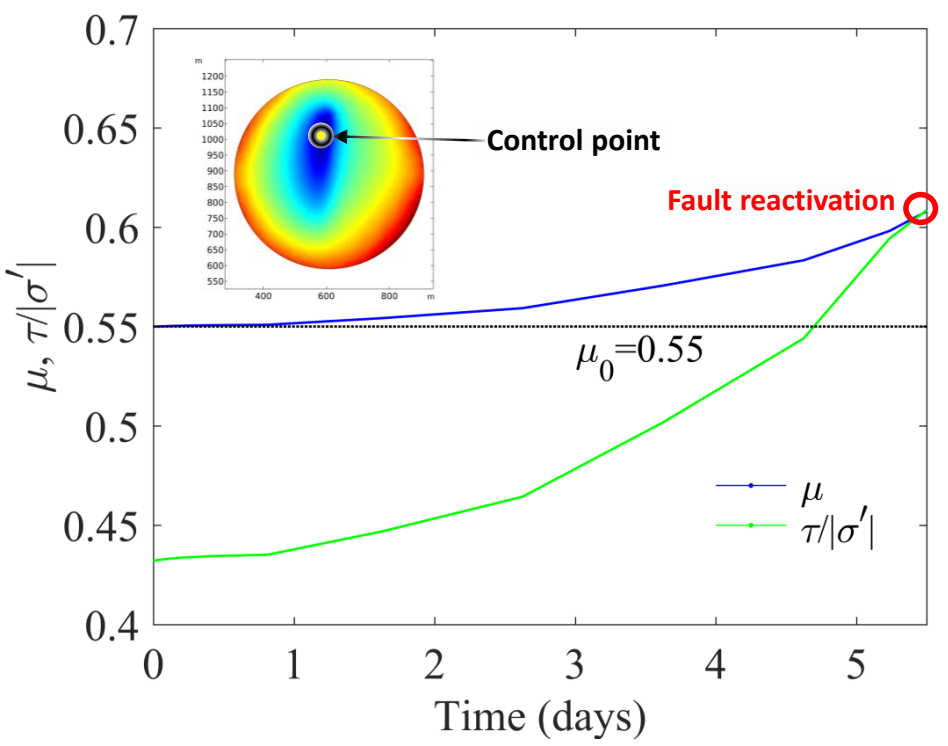

Figure 7. Evolution of the friction variables at the fault control point. The blue line represents the evolution of the friction coefficient $\mu$ as derived from the rate-and-state equations. The green line plots the evolution of the ratio $\tau /\left|\sigma^{\prime}\right|$. The slopes of both curves are related to the different flow-rate levels of the injection protocol.

\section{Conclusions}

Geothermal energy emerges as an alternative renewable energy to ensure access to affordable, reliable, sustainable, and modern energy for all the world. In most of the geothermal deposits, rock permeability at exploitation depths is very low, rendering geothermal projects economically infeasible. This drawback has been solved by the so-called Enhanced Geothermal Systems (EGS), where rock permeability is enhanced through the so-called rock stimulation. One of the most widely used techniques is hydro-shearing, which reactivates preexisting joints by initiating shear failure. Water is injected under high pressure, reducing normal stress across them and eventually triggering shear failure. A major environmental issue for these techniques is induced seismicity as a result of water injection.

Here, we have presented a finite element model for the simulation of fault reactivation in poroelastic media with rate-and-state friction law. Our model monolithically couples fluid flow, rock mechanics, heat transport, and rate-and-state friction. We have conducted three-dimensional simulations of fault reactivation with frictional strength governed by a Linker-Dieterich law, embedded in a poroelastic homogenous media, and driven by fluid injection. The Linker-Dieterich law accounts for the effect of effective stress rate on the friction evolution, and is able to explain the observed delays in fault reactivation.

We applied our model to simulate the hydro-shearing effects during the stimulation at the Basel-1 well at the Deep Heat Mining geothermal project in Basilea (Switzerland). We adopted as input the stress field and rock properties estimated for the main hydrogeological units at Basel-1, and simulated the stimulation phase using a transient well-head pressure and flow evolution similar to the values 
reported at the study site. Our three-dimensional model satisfactorily reproduced the registered injection flow rate and pressure injection, as well as the time of the fault reactivation.

Our simulated results indicate that thermal effects are negligible during the stimulation phase. Temperature changes occur in a small area around the injection well and do not reach the fault plane. Nevertheless, pressure changes, together with poroelastic effects, weaken the fault, leading eventually to fault reactivation and the onset of slip. Our model was able to reproduce the instant at which fault reactivation occurred at the Basel-1 site, demonstrating that the earthquake sequence that occurred in December 2006 in Basel was caused by the hydraulic stimulation of the geothermal reservoir.

Our methodology emerges as a useful tool for engineers, practitioners, and stakeholders to assess fault reactivation under real conditions of natural stresses, temperatures, and injection protocols. The application of our model to the DHM project in Basel has shown its ability to predict fault reactivation in a real case. Our model can also be useful for assessing new injection protocols, as well as stimulating and managing the operation of an EGS system in the short and long term.

Author Contributions: Investigation, S.A., D.S., J.C.M., and L.C.-F.

Funding: This research was supported by the Universidad Politécnica de Madrid through the special programme for young scientists under grant VJIDOCUPM19DSS ("Programa Propio de I+D+I de la Universidad Politécnica de Madrid. Convocatoria de ayuda dirigida a jóvenes investigadores doctores para fortalecer sus planes de investigación"). DSS gratefully acknowledges funding from the Fundación BBVA though Becas Leonardo a Investigadores y Creadores Culturales 2019 (Proyecto realizado con la Beca Leonardo a Investigadores y Creadores Culturales 2019 de la Fundación BBVA).

Conflicts of Interest: The authors declare no conflict of interest. The founders had no role in the design of the study; in the collection, analyses, or interpretation of data; in the writing of the manuscript, or in the decision to publish the results.

\section{References}

1. Colglazier, W. Sustainable development agenda: 2030. Int. J. Rock. Mech. Min. Sci. 2015, 349, $1048-1050$. [CrossRef] [PubMed]

2. MIT-Energy-Initiative. The Future of Geothermal Energy: Impact of Enhanced Geothermal Systems (EGS) on the United States in the 21st Century; Massachusetts Institute of Technology: Cambridge, MA, USA, 2006; pp. 1-372.

3. Mahbaz, S.; Dehghani-Sanij, A.; Dusseault, M.; Nathwani, J. Enhanced and integrated geothermal systems for sustainable development of Canada's northern communities. Sustain. Energy Technol. Assess. 2020, 37, 100565. [CrossRef]

4. Kazemi, A.; Mahbaz, S.; Dehghani-Sanij, A.; Dusseault, M.; Fraser, R. Performance Evaluation of an Enhanced Geothermal System in the Western Canada Sedimentary Basin. Renew. Sustain. Energ. Rev. 2019, 113, 109278. [CrossRef]

5. Kinney, C.; Dehghani-Sanij, A.; Mahbaz, S.; Dusseault, M.B.; Nathwani, J.S.; Fraser, R. Geothermal Energy for Sustainable Food Production in Canada's Remote Northern Communities. Energies 2019, 12, 4058. [CrossRef]

6. Soltani, M.; Kashkooli, F.M.; Dehghani-Sanij, A.R.; Kazemi, A.R.; Bordbar, N.; Farshchi, M.J.; Elmi, M.; Gharali, K.; Dusseault, M.B. A comprehensive study of geothermal heating and cooling systems. Sustain. Cities Soc. 2019, 44, 793-818. [CrossRef]

7. Soltani, M.; Moradi-Kashkooli, F.; Dehghani-Sanij, A.R.; Nokhosteen, A.; Ahmadi-Joughi, A.; Gharali, K.; Mahbaz, S.B.; Dusseault, M. A comprehensive review of geothermal energy evolution and development. Int. J. Green Energy 2019, 16, 971-1009. [CrossRef]

8. Rinaldi, A.P.; Rutqvist, J. Joint opening or hydroshearing? Analyzing a fracture zone stimulation at Fenton Hill. Geothermics 2019, 77, 83-98. [CrossRef]

9. Rinaldi, A.P.; Rutqvist, J.; Sonnenthal, E.L.; Cladouhos, T.T. Coupled THM Modeling of Hydroshearing Stimulation in Tight Fractured Volcanic Rock. Transport Porous Media 2014, 108, 131-150. [CrossRef]

10. Charléty, J.; Cuenot, N.; Dorbath, L.; Dorbath, C.; Haessler, H.; Frogneux, M. Large earthquakes during hydraulic stimulations at the geothermal site of Soultz-sous-Forêts. Int. J. Rock. Mech. Min. Sci. 2007, 44, 1091-1105, doi:10.1016/j.ijrmms.2007.06.003. [CrossRef] 
11. Baisch, S.; Vörös, R.; Weidler, R.; Wyborn, D. Investigation of fault mechanisms during geothermal reservoir stimulation experiments in the Cooper Basin, Australia. Bull. Seismol. Soc. Am. 2009, 99, 148-158. [CrossRef]

12. Fehler, M.C. Stress control of seismicity patterns observed during hydraulic fracturing experiments at the Fenton Hill hot dry rock geothermal energy site, New Mexico. Int. J. Rock. Mech. Min. Sci. 1989, 26, 211-219. [CrossRef]

13. Parker, R. The Rosemanowes HDR project 1983-1991. Geothermics 1999, 28, 603-615. [CrossRef]

14. Pine, R.J.; Batchelor, A.S. Downward migration of shearing in jointed rock during hydraulic injections. Int. J. Rock. Mech. Min. Sci. 1984, 21, 249-263. [CrossRef]

15. Ziagos, J.; Phillips, B.R.; Boyd, L.; Jelacic, A.; Stillman, G.; Hass, E. A technology roadmap for strategic development of enhanced geothermal systems. In Proceedings of the 38th Workshop on Geothermal Reservoir Engineering, Stanford, CA, USA, 11-13 February 2013; pp. 11-13.

16. Santillán, D.; Juanes, R.; Cueto-Felgueroso, L. Phase field model of fluid-driven fracture in elastic media: Immersed fracture formulation and validation with analytical solutions. J. Geophys. Res. Solid Earth 2017, 122, 2565-2589. [CrossRef]

17. Santillan, D.; Mosquera, J.; Cueto-Felgueroso, L. Fluid-driven fracture propagation in heterogeneous media: Probability distributions of fracture trajectories. Phys. Rev. E 2017, 96, 053002. [CrossRef]

18. Santillan, D.; Mosquera, J.; Cueto-Felgueroso, L. Phase-field model for brittle fracture. Validation with experimental results and extension to dam engineering problems. Eng. Fracture Mech. 2017, 178, 109-125. [CrossRef]

19. Santillán, D.; Juanes, R.; Cueto-Felgueroso, L. Phase field model of hydraulic fracturing in poroelastic media: Fracture propagation, arrest, and branching under fluid injection and extraction. J. Geophys. Res. Solid Earth 2018, 123, 2127-2155. [CrossRef]

20. Riahi, A.; Damjanac, B. Numerical study of hydro-shearing in geothermal reservoirs with a preexisting discrete fracture network. In Proceedings of the Thirty-Eighth Workshop on Geothermal Reservoir Engineering, Stanford, CA, USA, 11-13 February 2013.

21. Jeanne, P.; Guglielmi, Y.; Rutqvist, J.; Nussbaum, C.; Birkholzer, J. Permeability Variations Associated With Fault Reactivation in a Claystone Formation Investigated by Field Experiments and Numerical Simulations. J. Geophys. Res. Solid Earth 2018, 123, 1694-1710. [CrossRef]

22. Finnila, A.; Dershowitz, W.; Doe, T.; McLaren, R. Hydro-Shearing and Hydraulic Fracturing for Enhanced Geothermal Systems in Archetypical Normal, Strike-Slip, and Thrust Faulting Terrains. GRC Trans. 2015, 39, 1-19.

23. Norbeck, J.H.; McClure, M.W.; Horne, R.N. Field observations at the Fenton Hill enhanced geothermal system test site support mixed-mechanism stimulation. Geothermics 2018, 74, 135-149. [CrossRef]

24. Weingarten, M.; Ge, S.; Godt, J.W.; Bekins, B.A.; Rubinstein, J.L. High-rate injection is associated with the increase in US mid-continent seismicity. Science 2015, 348, 1336-1340. [CrossRef] [PubMed]

25. Horton, S. Disposal of hydrofracking waste fluid by injection into subsurface aquifers triggers earthquake swarm in central Arkansas with potential for damaging earthquake. Seismol. Res. Lett. 2012, 83, 250-260. [CrossRef]

26. Juanes, R.; Hager, B.H.; Herzog, H.J. No geologic evidence that seismicity causes fault leakage that would render large-scale carbon capture and storage unsuccessful. Proc. Natl. Acad. Sci. USA 2012, 109, E3623. [CrossRef] [PubMed]

27. Vilarrasa, V.; Carrera, J. Geologic carbon storage is unlikely to trigger large earthquakes and reactivate faults through which CO2 could leak. Proc. Natl. Acad. Sci. USA 2015, 112, 5938-5943. [CrossRef] [PubMed]

28. Brodsky, E.E.; Lajoie, L.J. Anthropogenic seismicity rates and operational parameters at the Salton Sea Geothermal Field. Science 2013, 341, 543-546. [CrossRef] [PubMed]

29. Majer, E.L.; Baria, R.; Stark, M.; Oates, S.; Bommer, J.; Smith, B.; Asanuma, H. Induced seismicity associated with enhanced geothermal systems. Geothermics 2007, 36, 185-222. [CrossRef]

30. Scholz, C.H. Earthquakes and friction laws. Nature 1998, 391, 37. [CrossRef]

31. Cueto-Felgueroso, L.; Vila, C.; Santillan, D.; Mosquera, J.C. Numerical modeling of injection-induced earthquakes using laboratory-derived friction laws. Water Resour. Res. 2018, 54, 1-27. [CrossRef]

32. Cueto-Felgueroso, L.; Santillán, D.; Mosquera, J.C. Stick-slip dynamics of flow-induced seismicity on rate and state faults. Geophys. Res. Lett. 2017, 44, 4098-4106. [CrossRef] 
33. De Simone, S.; Carrera, J.; Vilarrasa, V. Superposition approach to understand triggering mechanisms of post-injection induced seismicity. Geothermics 2017, 70, 85-97. [CrossRef]

34. McGarr, A. Maximum magnitude earthquakes induced by fluid injection. J. Geophys. Res. Solid Earth 2014, 119, 1008-1019. [CrossRef]

35. Mignan, A.; Karvounis, D.; Broccardo, M.; Wiemer, S.; Giardini, D. Including seismic risk mitigation measures into the Levelized Cost of Electricity in enhanced geothermal systems for optimal siting. Appl. Energy 2019, 238, 831-850. [CrossRef]

36. Scholz, C.H. The Mechanics of Earthquakes and Faulting; Cambridge University Press: Cambridge, UK, 2002.

37. Deichmann, N.; Giardini, D. Earthquakes Induced by the Stimulation of an Enhanced Geothermal System below Basel (Switzerland). Seismol. Res. Lett. 2009, 80, 784-798. [CrossRef]

38. Beck, M.; Seitz, G.; Class, H. Volume-based modelling of fault reactivation in porous media using a visco-elastic proxy model. Transp. Porous Media 2016, 114, 505-524. [CrossRef]

39. Borja, R.; Foster, C. Continuum mathematical modeling of slip weakening in geological systems. J. Geophys. Res. Solid Earth 2007, 112. [CrossRef]

40. Rutqvist, J.; Birkholzer, J.; Cappa, F.; Tsang, C.F. Estimating maximum sustainable injection pressure during geological sequestration of $\mathrm{CO} 2$ using coupled fluid flow and geomechanical fault-slip analysis. Energy Conv. Manag. 2007, 48, 1798-1807. [CrossRef]

41. Segura, J.M.; Carol, I. Coupled HM analysis using zero-thickness interface elements with double nodes. Part I: Theoretical model. Int. J. Numer. Anal. Meth. Geomech. 2008, 32, 2083-2101. [CrossRef]

42. Segura, J.M.; Carol, I. Coupled HM analysis using zero-thickness interface elements with double nodes. Part II: Verification and application. Int. J. Numer. Anal. Meth. Geomech. 2008, 32, 2103-2123. [CrossRef]

43. Ferronato, M.; Gambolati, G.; Janna, C.; Teatini, P. Numerical modelling of regional faults in land subsidence prediction above gas/oil reservoirs. Int. J. Numer. Anal. Meth. Geomech. 2008, 32, 633-657. [CrossRef]

44. Ghassemi, A.; Tao, Q. Thermo-poroelastic effects on reservoir seismicity and permeability change. Geothermics 2016, 63, 210-224. [CrossRef]

45. Jha, B.; Juanes, R. Coupled multiphase flow and poromechanics: A computational model of pore pressure effects on fault slip and earthquake triggering. Water Resour. Res. 2014, 50, 3776-3808. [CrossRef]

46. Morris, J.P.; Hao, Y.; Foxall, W.; McNab, W. A study of injection-induced mechanical deformation at the In Salah $\mathrm{CO}_{2}$ storage project. Int. J. Greenhouse Gas Control 2011, 5, 270-280. [CrossRef]

47. Rice, J.R. Heating and weakening of faults during earthquake slip. J. Geophys. Res. Solid Earth $2006,111$. [CrossRef]

48. Dieterich, J.H. Earthquake nucleation on faults with rate-and state-dependent strength. Tectonophysics 1992, 211, 115-134. [CrossRef]

49. Dieterich, J.H.; Linker, F.M. Fault Stability Under Conditions of Variable Normal Stress. Geophys. Res. Lett. 1992, 19, 1691-1694. [CrossRef]

50. Kilgore, B.; Beeler, N.M.; Lozos, J.; Oglesby, D. Rock friction under variable normal stress. J. Geophys. Res. Solid Earth 2017, 122, 7042-7075. [CrossRef]

51. Andrés, S.; Santillán, D.; Mosquera, J.C.; Cueto-Felgueroso, L. Delayed weakening and reactivation of rate-and-state faults driven by pressure changes due to fluid injection. J. Geophys. Res. Solid Earth 2019, doi:10.1029/2019JB018109. [CrossRef]

52. Wyss, R.; Link, K. Actual Developments in Deep Geothermal Energy in Switzerland. In Proceedings of the World Geothermal Congress 2015, Melbourne, Australia, 19-25 April 2015.

53. Meier, P.M.; Alcolea Rodríguez, A.; Bethmann, F. Lessons Learned from Basel: New EGS Projects in Switzerland Using Multistage Stimulation and a Probabilistic Traffic Light System for the Reduction of Seismic Risk. In Proceedings of the World Geothermal Congress 2015, Melbourne, Australia, 19-25 April 2015.

54. Swiss Seismological Service. DHM Project Description. 2019. Available online: http://www. seismo.ethz.ch/en/earthquakes/monitoring/geothermal-energy-basel/Project-Description/ (accessed on 3 December 2019).

55. Ladner, F.; Haring, M. Hydraulic Characteristics of the Basel 1 Enhanced Geothermal System. GRC Trans. 2009, 33, 199-203.

56. Haring, M.O.; Schanz, U.; Ladner, F.; Dyer, B.C. Characterisation of the Basel 1 enhanced geothermal system. Geothermics 2008, 37, 469-495. [CrossRef] 
57. Jacquey, A.B.; Cacace, M.; Blöcher, G.; Watanabe, N.; Huenges, E.; Scheck-Wenderoth, M. Thermo-poroelastic numerical modelling for enhanced geothermal system performance: Case study of the Groß Schönebeck reservoir. Tectonophysics 2016, 684, 119-130. [CrossRef]

58. Kim, S.; Hosseini, S.A. Hydro-thermo-mechanical analysis during injection of cold fluid into a geologic formation. Int. J. Rock. Mech. Min. Sci. 2015, 77, 220-236. [CrossRef]

59. Li, C.; Laloui, L. Coupled multiphase thermo-hydro-mechanical analysis of supercritical $\mathrm{CO}_{2}$ injection: Benchmark for the In Salah surface uplift problem. Int. J. Greenhouse Gas Control 2016, 51, 394-408. [CrossRef]

60. Rutqvist, J.; Birkholzer, J.; Tsang, C.F. Coupled reservoir-geomechanical analysis of the potential for tensile and shear failure associated with $\mathrm{CO}_{2}$ injection in multilayered reservoir-caprock systems. Int. J. Rock. Mech. Min. Sci. 2008, 45, 132-143. [CrossRef]

61. De Simone, S.; Vilarrasa, V.; Carrera, J.; Alcolea, A.; Meier, P. Thermal coupling may control mechanical stability of geothermal reservoirs during cold water injection. Phys. Chem. Earth 2013, 64, 117-126. [CrossRef]

62. Vidal-Gilbert, S.; Tenthorey, E.; Dewhurst, D.; Ennis-King, J.; Van Ruth, P.; Hillis, R. Geomechanical analysis of the Naylor Field, Otway Basin, Australia: Implications for $\mathrm{CO}_{2}$ injection and storage. Int. J. Greenhouse Gas Control 2010, 4, 827-839. [CrossRef]

63. Vilarrasa, V.; Bolster, D.; Olivella, S.; Carrera, J. Coupled hydromechanical modeling of $\mathrm{CO}_{2}$ sequestration in deep saline aquifers. Int. J. Greenhouse Gas Control 2010, 4, 910-919. [CrossRef]

64. Vilarrasa, V.; Olivella, S.; Carrera, J.; Rutqvist, J. Long term impacts of cold $\mathrm{CO}_{2}$ injection on the caprock integrity. Int. J. Greenhouse Gas Control 2014, 24, 1-13. [CrossRef]

65. Bowden, F.; Tabor, D. The Friction and Lubrication of Solids I; Clarendon Press: London, UK, 1950.

66. Baumberger, T.; Caroli, C. Solid friction from stick-slip down to pinning and aging. Adv. Phys. 2006, 55, 279-348. [CrossRef]

67. Barber, J.R. Multiscale Surfaces and Amontons' Law of Friction. Tribol. Lett. 2013, 49, 539-543. [CrossRef]

68. Dieterich, J.H. Modeling of rock friction: 1. Experimental results and constitutive equations. J. Geophys. Res. Solid Earth 1979, 84, 2161-2168. [CrossRef]

69. Ruina, A. Slip instability and state variable friction laws. J. Geophys. Res. Solid Earth 1983, 88, 10359-10370. [CrossRef]

70. Putelat, T.; Dawes, J.; Willis, J.R. On the microphysical foundations of rate-and-state friction. J. Mech. Phys. Solids 2011, 59, 1062-1075. [CrossRef]

71. Marone, C. Laboratory-derived friction laws and their application to seismic faulting. Annu. Rev. Earth Planet. Sci. 1998, 26, 643-696. [CrossRef]

72. Dieterich, J.H. Time-dependent friction and the mechanics of stick-slip. Pure Appl. Geophys. 1978, 116, 790-806. [CrossRef]

73. Rice, J.R.; Lapusta, N.; Ranjith, K. Rate and state dependent friction and the stability of sliding between elastically deformable solids. J. Mech. Phys. Solids 2001, 49, 1865-1898. [CrossRef]

74. Nakatani, M. Conceptual and physical clarification of rate and state friction: Frictional sliding as a thermally activated rheology. J. Geophys. Res. 2001, 106, 13347-13380. [CrossRef]

75. Rathbun, A.P.; Marone, C. Symmetry and the critical slip distance in rate and state friction laws. J. Geophys. Res. Solid Earth 2013, 118, 3728-3741. [CrossRef]

76. Bhattacharya, P.; Rubin, A.; Bayart, E.; Savage, H.; Marone, C. Critical evaluation of state evolution laws in rate and state friction: Fitting large velocity steps in simulated fault gouge with time-, slip-, and stress-dependent constitutive laws. J. Geophys. Res. Solid Earth 2015, 120, 6365-6385. [CrossRef]

77. Nagata, K.; Nakatani, M.; Yoshida, S. A revised rate- and state-dependent friction law obtained by constraining constitutive and evolution laws separately with laboratory data. J. Geophys. Res. 2012, 117, B02314. [CrossRef]

78. Linker, F.M.; Dieterich, J.H. Effects of Variable Normal Stress on Rock Friction: Observations and Constitutive Equations. J. Geophys. Res. 1992, 97, 4923-4940. [CrossRef]

79. Hong, T.; Marone, C. Effects of normal stress perturbations on the frictional properties of simulated faults. Geochem. Geophys. Geosyst. 2005, 6, 1-19. [CrossRef]

80. Kilgore, B.; Lozos, J.; Beeler, N.; Oglesby, D. Laboratory Observations of Fault Strength in Response to Changes in Normal Stress. J. Appl. Mech. 2012, 79, 03100701-03100710. [CrossRef]

81. Perfettini, H.; Molinari, A. A micromechanical model of rate and state friction: 2. Effect of shear and normal stress changes. J. Geophys. Res. Solid Earth 2017, 122, 2638-2652. 
82. Perfettini, H.; Schmittbuhl, J.; Rice, R.J.; Cocco, M. Frictional response induced by time-dependent fluctuations of the normal loading. J. Geophys. Res. 2001, 106, 13455-13472. [CrossRef]

83. Yang, Z.; Zhang, H.P.; Marder, M. Dynamics of static friction between steel and silicon. Proc. Natl. Acad. Sci. USA 2008, 105, 13264-13268. [CrossRef] [PubMed]

84. Tal, Y.; Hager, B.H.; Ampuero, J.P. The effects of fault roughness on the earthquake nucleation process. J. Geophys. Res. Solid Earth 2018, 123, 437-456. [CrossRef]

85. Biot, M.A. General theory of three-dimensional consolidation. J. Appl. Phys. 1941, 12, 155-164. [CrossRef]

86. Rice, J.R.; Cleary, M.P. Some Basic Stress Diffusion Solutions for Fluid-Saturated Elastic Porous Media With Compressible Constituents. Rev. Geophys. Space Phys. 1976, 14, 227-241. [CrossRef]

87. Fourier, J.B.J. Théorie Analytique de la Chaleur; Chez Firmin Didot Pére et Fils: Paris, France, 1822.

88. Deichmann, N.; Krafta, T.; Evans, K. Identification of faults activated during the stimulation of the Basel geothermal project from cluster analysis and focal mechanisms of the larger magnitude events. Geothermics 2014, 52, 84-97. [CrossRef]

89. Gaucher, E.; Schoenball, M.; Heidbach, O.; Zang, A.; Fokker, P.A.; van Wees, J.D.; Kohl, T. Induced seismicity in geothermal reservoirs: A review of forecasting approaches. Renew. Sustain. Energy Rev. 2015, 52, 1473-1490. [CrossRef]

90. Cacace, M.; Jacquey, A. Flexible parallel implicit modelling of coupled thermal-hydraulic-mechanical processes in fractured rocks. Solid Earth 2017, 8, 921-941. [CrossRef]

91. COMSOL. COMSOL Multiphysics Structural Mechanics Module User's Guide v5.2a; Comsol: Stockholm, Sweden, 2016.

(C) 2019 by the authors. Licensee MDPI, Basel, Switzerland. This article is an open access article distributed under the terms and conditions of the Creative Commons Attribution (CC BY) license (http:/ / creativecommons.org/licenses/by/4.0/). 